\title{
Knowledge Creation and Innovation Performance: An Exploration of Competing Perspectives on Organizational Systems
}

\author{
Dinesh N. Iyer, ${ }^{1, *}$, Barton M. Sharp ${ }^{2}$, Thomas H. Brush ${ }^{3}$ \\ ${ }^{1}$ Rutgers School of Business-Camden, USA \\ ${ }^{2}$ Department of Management, Northern Illinois University, USA \\ ${ }^{3}$ Krannert School of Management, Purdue University, USA
}

Copyright $\subseteq 2017$ by authors, all rights reserved. Authors agree that this article remains permanently open access under the terms of the Creative Commons Attribution License 4.0 International License

\begin{abstract}
This study is an effort towards understanding the role of organizational systems in innovation performance. We consider two distinct perspectives of organizational systems in terms of knowledge creation and innovation performance. One perspective considers organizational systems as serving to recombine existing knowledge to create new knowledge and thus value, while the other views organizational systems as a tool for implementing knowledge created by individual members in a value-adding way. The study develops a model in which organizational systems mediate the relationship between knowledge and organizational innovation performance in order to better understand how organizations themselves, as distinct from the individuals which make up the organization, contribute to innovation. The study applies Structural Equation Modeling (SEM) to plant level data to explore the importance of organizational systems on knowledge transfer and performance. The findings suggest that organizational systems mediate the relationship between knowledge transfer and innovation performance, supporting the idea of the organization as a central actor in knowledge creation. Also, internal knowledge sources were found to contribute more to the knowledge transfer within the firm when compared to external knowledge sources.
\end{abstract}

Keywords Knowledge Transfer, Organizational Systems, Innovation Performance

\section{Introduction}

The importance of knowledge as a strategically important resource and as a source of competitive advantage is widely accepted (Conner and Prahalad, 1996; Grant, 1996; Kogut and Zander, 1992; Szulanski et al., 2016). Knowledge and the underlying intellectual resources of a firm are a fundamental underpinning of innovation as it is primarily dependent on the ability of the organization to recombine knowledge and resources in novel ways to achieve a sustainable competitive advantage. Organizational units' ability to learn from each other and transfer knowledge is integral to being more productive and competitive (Argote, 2013). As such, the capability of an organization and its systems to absorb, transfer, replicate, and combine knowledge plays a significant role in determining its ability to generate innovative new ideas, products, or processes. In fact, this ability to transfer knowledge effectively between organizational units is necessary for superior performance and productivity, whereas the organizations lacking this ability are considered to be at a disadvantage (Almeida and Kogut, 1999; Argote et al., 1990; Hansen, 2002; Inkpen and Tsang, 2005). An important component of innovation then rests on the firm's ability to create, replicate and transfer knowledge and this process is riddled with persistent difficulties (Szulanski, 1996). Furthermore, this ability is affected both by the type of knowledge as well as how the organization manages it. Hence the organizational systems that support the maintenance and transfer of knowledge are considered to be of utmost importance for innovation and performance. However, there remains some disagreement regarding the level at which knowledge creation takes place and the role played by the organization versus that of the individual members of the organization in the creation of new knowledge.

One view, espoused by Kogut and Zander (1992), suggests that the organization itself is in possession of the recombinatory capabilities which lead to innovation through the combination of previously unconnected pieces of knowledge. This primacy of the organization springs in part from the recognition that organizational capabilities are to some extent robust to the entrance and exit of employees, 
indicating that the organization itself is in possession of both "know-what" (explicit knowledge) and "know-how" (implicit or tacit knowledge). Organizational knowledge is a product of the combination of explicit and tacit knowledge (Nonaka, 1994; Polanyi, 1966). Under this somewhat anthropomorphic view of organizations and knowledge, individual employees serve as important and yet critically limited inputs into a process which unfolds at the organizational level.

In contrast, Grant (1996) proposes that knowledge creation is the domain of individuals, and the organization is merely a tool of knowledge application. This alternative perspective is motivated in part by the previous work of Simon (1991, p. 125) who holds that "All learning takes place inside individual human heads; an organization learns in only two ways: (a) by the learning of its members, or (b) by ingesting new members who have knowledge the organization didn't previously have". This view suggests instead that the organizations cannot recombine knowledge, only the people within these organizations have that ability. The role of the organization then is to offer an environment of low-powered incentives where knowledgeable individuals, who have by necessity become experts in certain areas of inquiry, can come together to pool their expertise for the purpose of economic activity without fear of expropriation. Far from playing a primary role in innovation or knowledge creation, the organization in this schema serves only as a locus of coordination among individuals rather than a tool of creation.

Both perspectives recognize the value of innovation and the relevance of gaining knowledge, or "learning", as a first step towards realizing that value. Tacit knowledge and its integral role in the both the creation and transfer of knowledge is acknowledged by both viewpoints (Grant, 1996; Kogut and Zander, 1992). In either case, it should be clear that organizations which "learn" more effectively than others will be better positioned to innovate, and that those innovations should ultimately result in improved organizational performance. From both theoretical and practical perspectives it is important that we tease apart the alternate and classic views on the role of the organization in this process originally espoused by Kogut \& Zander (1992) and Grant (1996) in order to better understand where innovations come from, and to be able to offer more detailed, actionable guidance to managers who wish to maximize the benefits their organizations receive from innovation. Whether learning and knowledge recombination takes place at the level of the individual or the level of the organization will to a great extent points us towards developing more efficient and effective structures and policies to improve organizational outcomes.

This study is an effort towards reconciling these seemingly competing viewpoints of the role of organizational systems in knowledge creation and innovation. We develop a model in which organizational systems mediate the relationship between knowledge and organizational innovation performance in order to better understand how organizations themselves, distinct from the individuals which make up the organization, contribute to innovation. This will not only enhance our theoretical understanding of the phenomenon but will also allow future scholars to develop practitioner-oriented approaches to improving learning and innovation in a more targeted way.

\section{Hypotheses Development}

Kogut and Zander (1992) argue that the ability of the organization to recombine existing and new knowledge creates new capabilities. These new capabilities broaden the opportunity set that a firm has and is a source of competitive advantage. Grant (1996), on the other hand, argues that the role of the organization is to simply apply the knowledge that is created, recombined, and held by the individuals. In this view, the role of organizational systems is one of implementation rather than creation. In an effort to make the distinction between these viewpoints we juxtapose these two interpretations in the literature, at their extreme, to glean an understanding of the importance and role of organizational systems.

We can approach the question of whether organizational systems act as either facilitators of knowledge creation (Zander and Kogut, 1995) or knowledge implementation (Grant, 1996) by considering the direct and indirect effects of knowledge transfer on innovation performance through the organizational system. If firms exist primarily to implement the valuable new ideas which originate at the level of the individual organization members, we would not expect organizational systems to significantly affect a firm's ability to innovate. Rather, we would expect that the ability to innovate would rest entirely on the knowledge resident in the minds of the individuals and the extent to which that knowledge is shared through the organization. However, if the organizational systems serve a vital role in the very process of recombination which leads to innovation, then we would expect those systems to mediate the relationship between knowledge transfer and innovation performance. In other words, if recombination of existing knowledge is a primary source of innovation, and that recombination takes place at the level of the individual, then all that should be necessary for innovation to happen is for there to be knowledge transfer within the organization. This transfer of knowledge creates the opportunity for previously disconnected pieces of information to come into contact with each other. If, on the other hand, the organization itself plays a central role in recombination and innovation, we would expect the effects of knowledge transfer to be modified by the systems at the organizational level. Specifically we consider the possibility that knowledge transfer, rather than being a direct antecedent to innovation, would instead feed into the organizational systems which in turn directly affect innovation. We test these alternative views by means of two 
competing hypotheses:

Hypothesis 1a: Knowledge transfer will have a direct effect on innovation performance (Grant 1996)

Hypothesis 1b: Organizational systems will mediate the relationship between knowledge and innovation performance (Kogut \& Zander 1992)

Next, we recognize that regardless of where the locus of knowledge creation resides, new knowledge invariably rests on the shoulders of what has come before. Therefore, for an organization to innovate or create new knowledge there must be some mechanism by which existing knowledge is recognized, valued, and absorbed (Cohen and Levinthal, 1990). This existing knowledge can reside internally in the form of employee expertise or codified organizational memories, or it can reside beyond the boundaries of the organization. Knowledge from outside firm boundaries is seen as a necessary component in a firm's ability to initiate change and other enhancements. Menon and Pfeffer (2003) observed the tendency of managers to value external knowledge more highly than internal sources of knowledge. This tendency is driven by a) the lack of incentive in valuing an insider's knowledge, and b) the scarcity of external knowledge. The scarcity of external knowledge and the difficulty in accessing it also compounds the perceived value of external (Cialdini, 2001) over internal knowledge. On the other hand, the not-invented-here (NIH) syndrome suggests that while external knowledge may be critical for firm innovativeness, there may be significant internal resistance within the organization (Katz and Allen, 1982) to this knowledge. Furthermore, the firm may be myopic with respect to the importance of the external knowledge and may significantly discount its relevance. In sum however, external knowledge that is available to one firm is equally available to all firms and thus is less likely, in isolation, to offer significant advantage to any particular organization (Barney, 1991), whereas the internal knowledge is firm specific. There is also the question of acquisition. Szulanski (1996) points out the numerous impediments that make the transfer of knowledge among members of an organization difficult. Impediments will only be magnified when considering the potential for inter-organizational transfer. Despite the managerial perception that external knowledge is more valuable, it is also likely to be far more difficult to acquire. Combining these viewpoints, we suggest that internally generated knowledge would be more likely to be transferred within the organization than would knowledge from external knowledge.

Hypothesis 2: Internal sources of knowledge will contribute significantly more to a firm's knowledge base than will external sources of knowledge.

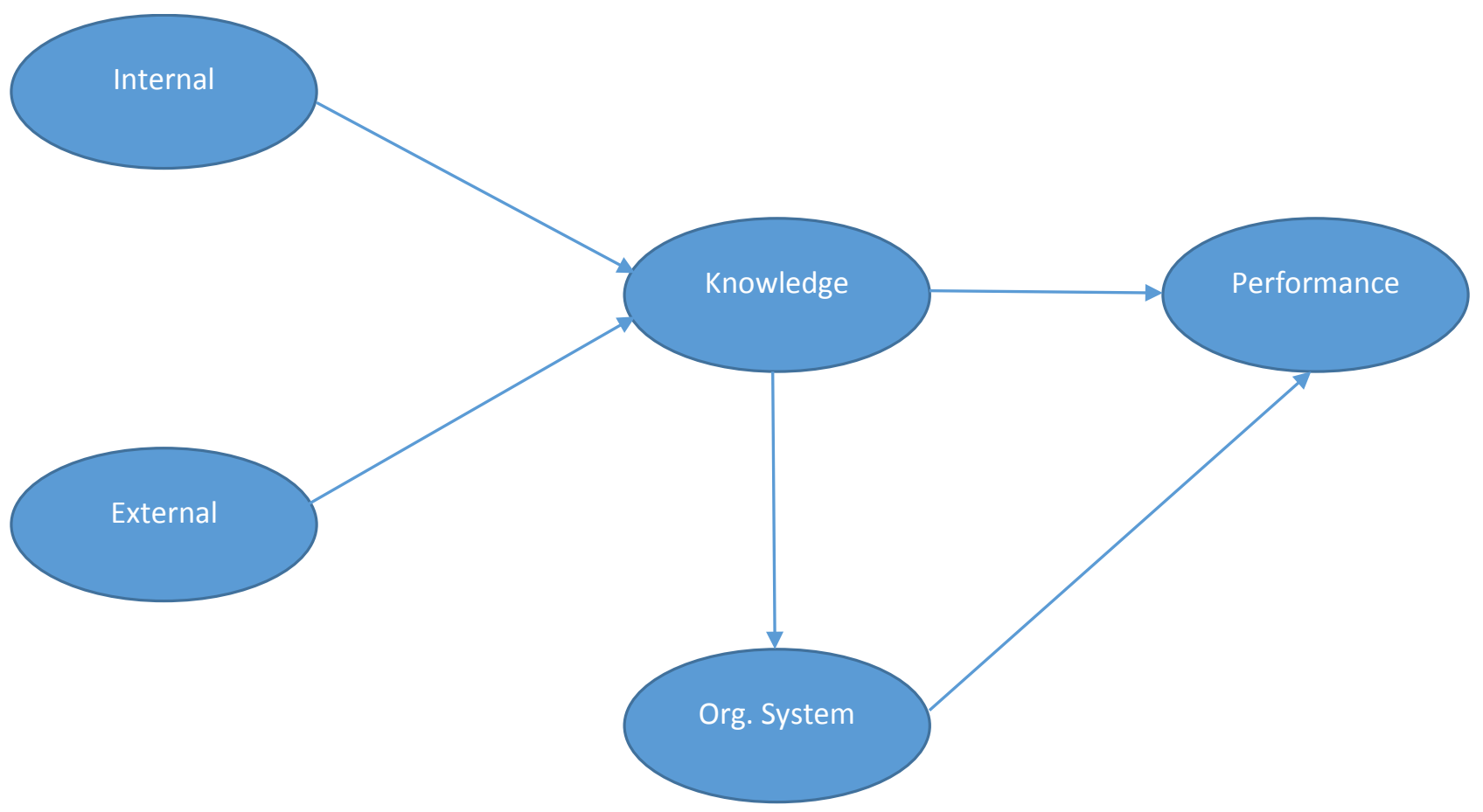

Figure 1 


\section{Methods}

\subsection{Data}

The data used to test the discussed model comes from the Global Manufacturing Networks Survey conducted by Professors Brian Talbot and Aneel Karnani of the Graduate School of Business Administration at the University of Michigan. The survey was completed by business unit managers from over 200 firms representing 31 countries (see Maritan et al., 2004). The average firm size was about 1200 employees. The survey included questions that asked the respondents to indicate the roles that various sources of knowledge and methods of knowledge transfer play in their business unit as well as their evaluation of the standardization of plants and their performance relative to world standards in their respective industries. All items are asked on a 6-point Likert scale with values ranging from zero to five $(0=$ small extent to $5=$ large extent). The survey items used in the present paper in the final model are available in the appendix and the full survey is available from the survey authors upon request.

\subsection{Variables}

Internal Knowledge represents the privileged and internally developed information that a firm possesses. This construct is measured using survey responses to questions that determine the use of technology from sources such as work force and plant level R\&D. External knowledge represents information widely available to most firms. This construct is measured using responses to questions that determine the use of technology from sources such as customers, competitors, suppliers and government. The appendix only refers to the significant factors used in the final model for ease in presentation.

Knowledge transfer is measured using responses to four questions which capture both the tacit and explicit dimensions of knowledge (Polanyi, 1966). Explicit knowledge is knowledge which is resident in a tangible form which can be shared and accessed through written materials. In other words this represents the type of knowledge that can be codified. This construct is measured using responses to questions regarding the use of internal documentation, engineering meetings and $\mathrm{CAD} / \mathrm{CAM}$ systems. Tacit knowledge is primarily gained through experience, resides within the minds of the organizational members, and cannot be easily transferred through manuals or in other codified forms. Interpersonal communication is a major component of being able to transfer tacit knowledge (Edmondson et al., 2000; Szulanski, 1996). Tacit knowledge is normally transferred through processes such as mentorship, apprenticeship, and repeated practice over a period of time (Nonaka, 1994; Nonaka and Takeuchi, 1996; Spender, 1996). This construct is measured using responses to questions regarding the use of formal training programs, project teams and transfer or re-assignment of personnel. Hence the above measures are designed to capture the extent to which both explicit and tacit knowledge is transferred within the organization.

Organizational systems represent the standardization across plants within a firm. We use this as a proxy for organizational systems which could directly contribute to innovation since it is through standardization processes that the organization itself would ensure that what is known in one part is known in all, and thus create more fertile opportunities for cross-pollination of ideas. This is distinct from knowledge transfer in that it carries with it an element of enforcement whereby the powers that be in an organization direct attention to the processes and knowledge being standardized. Without standardization the knowledge held by each individual and operating unit is more likely to be isolated from the rest of the organization. Or, more to the point of the current study, in the absence of organizational systems designed specifically to standardize what is known across the organization, the process of innovation through recombination would depend to a much greater extent on the efforts of individuals to share and seek out recombinatory opportunities. This construct is measured from responses to questions regarding product standardization, technology transfer, central production planning, and common quality standards.

Innovation Performance is measured using questions in which respondents were asked to compare their plant's performance in process innovation, product innovation, and product quality relative to the "world standard". In other words, they were asked to rate their performance compared to the best possible performance.

\section{Results}

An exploratory factor analysis was conducted on approximately half of the data set $(\mathrm{n}=100)$ to determine which survey items best represent the constructs used in the model. This analysis was conducted using maximum likelihood estimation. The items emerging from this analysis are consistent with the conceptualization of the constructs described earlier. A confirmatory factor analysis was subsequently conducted in AMOS on the other half of the data set $(\mathrm{n}=109)$ to confirm these factor loadings. Each of the factor loadings was above the commonly accepted standard of 0.40 , with the lowest loading at 0.51 , suggesting that the items are good measures of the latent constructs. Please note that the results presented hereafter have been achieved using the full $(n=209)$ data set so as to more adequately test the model.

Table 1 shows the descriptive statistics of these individual manifest variables, which demonstrates that none of the normality, skewness, or kurtosis assumptions necessary for structural equation modeling are violated. Lack of univariate normality occurs when the skew index is above 3 and kurtosis index is above 10 . It should be noted that the descriptive statistics presented in this table only represent the 
data points for which there was no missing data, of which there were relatively few. The results pertaining to the structural model were achieved using the standard imputation option in AMOS. The correlation matrix is available in Table 2 .

Table 2 provides a correlation matrix of the manifest variables used to develop the latent constructs. As discussed earlier, tacit and explicit knowledge are regularly conceptualized in the research literature as two separate constructs. However, the literature also suggests that these constructs tend to be highly correlated. In other words, it is unlikely that a firm will possess a great deal of tacit knowledge and very little explicit knowledge. Rather, a firm is more likely to possess either large or small amounts of both types of knowledge. Due to this high correlation, the aggregation of the tacit and explicit knowledge into a single knowledge base is not only consistent with the research literature, but helpful in producing a structural equation model that is both parsimonious and will also offer a good fit. Therefore, the model presented is consistent with the conceptual model discussed earlier, offering overall knowledge base as a single construct.

Table 3 a provides the standardized regression weights and statistical significance, and Table $3 \mathrm{~b}$ provides the fit measures associated with the tested model. The structural model displays factor loadings and can be seen in Figure 2. Only the significant manifest variables are reported. All of the standardized factor loadings exceed the commonly accepted 0.4 criterion, suggesting that the manifest variables are appropriate measures of the latent constructs used in the model. In general, the proposed model fits well and appears to be a plausible model of the relationships between the sources of knowledge, knowledge base, organizational system, and performance of a firm. This goodness of fit is seen in the fit measures associated with the model. The chi-square value of 85.306 with 71 degrees of freedom is non-significant with a $p$-value of 0.118 , suggesting that the model is a good fit. Additionally, the goodness of fit indices further demonstrate the plausibility of the model in that all values are above the 0.95 level (Tucker-Lewis Index $=0.997$, Comparative fit index $=0.998$ ). Finally, the RMSEA is 0.031 .

Table 1. Descriptive statistics

\begin{tabular}{|c|c|c|c|c|c|c|}
\hline Construct & $\mathbf{N}$ & Mean & Std. Dev & Variance & Skewness & Kurtosis \\
\hline \multicolumn{7}{|l|}{ Internal sources of knowledge } \\
\hline 1 Plant level R\&D, Manufacturing, Engineering etc: PLANTR_D & 206 & 3.56 & 1.30 & 1.70 & -0.69 & -0.37 \\
\hline 2 Source of technology from work force: WRKFORCE & 206 & 2.81 & 1.48 & 2.20 & -0.33 & -0.73 \\
\hline \multicolumn{7}{|l|}{ External sources of knowledge } \\
\hline 3 Source of technology from customer: CUSTOMER & 206 & 2.92 & 1.39 & 1.95 & -0.38 & -0.58 \\
\hline 4 Source of technology from supplier: SUPPLIER & 206 & 2.61 & 1.41 & 1.98 & -0.19 & -0.75 \\
\hline 5 Source of technology from competitor: COMPETIT & 206 & 2.46 & 1.42 & 2.02 & -0.05 & -0.82 \\
\hline 6 Source of technology from government: GOVERNME & 206 & 1.47 & 1.45 & 2.10 & 0.75 & -0.41 \\
\hline \multicolumn{7}{|l|}{ Knowledge transfer: Tacitness of knowledge base } \\
\hline 7 Through formal training programs: TRAINING & 207 & 3.06 & 1.11 & 1.23 & -0.40 & -0.27 \\
\hline 8 Through short-term reassignment of personnel: REASSIGN & 206 & 2.70 & 1.20 & 1.44 & -0.56 & 0.12 \\
\hline 9 Through long-term personnel transfer: TRANSFER & 206 & 2.57 & 1.34 & 1.80 & -0.18 & -0.61 \\
\hline 10 Through project teams and task forces: PROJTEAM & 206 & 3.91 & 1.02 & 1.04 & -0.89 & 0.52 \\
\hline \multicolumn{7}{|l|}{ Knowledge transfer: Explicitness of knowledge base } \\
\hline 11 Through internal documents-manuals, reports etc: DOCUMENT & 207 & 4.02 & 0.96 & 0.93 & -0.94 & 0.60 \\
\hline 12 Through engineering meetings: ENGMTNGS & 207 & 3.30 & 1.14 & 1.31 & -0.63 & 0.04 \\
\hline 13 Use of Cad/Cam systems: CADCAM & 206 & 2.42 & 1.51 & 2.29 & -0.25 & -0.93 \\
\hline \multicolumn{7}{|l|}{ Organizational systems and the level of standardization } \\
\hline 14 Extent of product standardization: PRODSTNR & 205 & 3.94 & 1.25 & 1.57 & -1.34 & 1.25 \\
\hline 15 Extent of technology transfer across plants: TECHTRNS & 202 & 3.27 & 1.15 & 1.33 & -0.70 & 0.66 \\
\hline 16 Common quality standards across all plants: QLTYSTNR & 204 & 3.82 & 1.39 & 1.94 & -1.22 & 0.67 \\
\hline 17 Similar production planning systems: PRODPLNS & 205 & 2.88 & 1.41 & 1.99 & -0.29 & -0.84 \\
\hline \multicolumn{7}{|l|}{ Performance } \\
\hline 18 Product quality: PRODQLTY & 208 & 4.28 & 0.92 & 0.84 & -1.96 & 5.89 \\
\hline 19 Process innovation: PROCINNO & 206 & 3.66 & 1.09 & 1.19 & -0.95 & 1.48 \\
\hline 20 Product innovation: PRODINNO & 204 & 3.65 & 1.24 & 1.55 & -0.91 & 0.58 \\
\hline
\end{tabular}


Table 2. Correlation Matrix

\begin{tabular}{|c|c|c|c|c|c|c|c|c|c|c|c|c|c|c|c|c|c|c|c|c|}
\hline & & 1 & 2 & 3 & 4 & 5 & 6 & 7 & 8 & 9 & 10 & 11 & 12 & 13 & 14 & 15 & 16 & 17 & 18 & 19 \\
\hline & PLANTR_D & 1 & & & & & & & & & & & & & & & & & & \\
\hline 2 & WRKFORCE & 0.57 & 1 & & & & & & & & & & & & & & & & & \\
\hline 3 & CUSTOMER & 0.21 & 0.28 & 1 & & & & & & & & & & & & & & & & \\
\hline 4 & SUPPLIER & 0.35 & 0.54 & 0.30 & 1 & & & & & & & & & & & & & & & \\
\hline 5 & COMPETIT & 0.14 & 0.20 & 0.49 & 0.32 & 1 & & & & & & & & & & & & & & \\
\hline 6 & GOVERNME & 0.04 & 0.13 & 0.38 & 0.20 & 0.47 & 1 & & & & & & & & & & & & & \\
\hline 71 & DOCUMENT & 0.29 & 0.30 & 0.15 & 0.20 & 0.20 & -0.01 & 1 & & & & & & & & & & & & \\
\hline 91 & PROJTEAM & 0.34 & 0.28 & 0.25 & 0.34 & 0.23 & 0.08 & 0.40 & 0.46 & 1 & & & & & & & & & & \\
\hline $10^{-}$ & TRAINING & 0.28 & 0.34 & 0.25 & 0.35 & 0.23 & 0.14 & 0.36 & 0.32 & 0.50 & 1 & & & & & & & & & \\
\hline 111 & REASSIGN & 0.30 & 0.44 & 0.18 & 0.37 & 0.14 & 0.04 & 0.37 & 0.42 & 0.49 & 0.54 & 1 & & & & & & & & \\
\hline 12 & TRANSFER & 0.27 & 0.39 & 0.24 & 0.36 & 0.26 & 0.07 & 0.36 & 0.41 & 0.41 & 0.41 & 0.55 & 1 & & & & & & & \\
\hline 13 & CADCAM & 0.39 & 0.38 & 0.33 & 0.35 & 0.25 & -0.03 & 0.27 & 0.42 & 0.40 & 0.27 & 0.40 & 0.44 & 1 & & & & & & \\
\hline 141 & PRODSTNR & 0.00 & 0.21 & 0.01 & 0.11 & 0.14 & 0.06 & 0.25 & 0.06 & 0.10 & 0.20 & 0.13 & 0.23 & 0.07 & 1 & & & & & \\
\hline 151 & TECHTRNS & 0.13 & 0.25 & 0.11 & 0.28 & 0.14 & 0.15 & 0.17 & 0.19 & 0.24 & 0.19 & 0.24 & 0.14 & 0.16 & 0.42 & 1 & & & & \\
\hline $18 \mathrm{~F}$ & PRODQLTY & -0.12 & -0.04 & -0.05 & -0.19 & -0.05 & 0.07 & -0.03 & -0.14 & -0.06 & -0.16 & -0.11 & -0.10 & -0.01 & 0.21 & 0.09 & 0.07 & 0.04 & 1 & \\
\hline $19 \mathrm{P}$ & PROCINNO & -0.07 & -0.01 & 0.02 & -0.17 & -0.02 & 0.11 & -0.03 & 0.01 & 0.06 & 0.04 & -0.05 & 0.06 & 0.02 & 0.16 & 0.09 & 0.07 & 0.08 & 0.43 & 1 \\
\hline $20 \mathrm{~F}$ & PRODINNO & -0.08 & -0.02 & 0.05 & -0.04 & 0.04 & 0.14 & -0.07 & 0.00 & 0.06 & 0.04 & -0.09 & -0.01 & 0.10 & 0.11 & 0.13 & 0.04 & 0.13 & 0.41 & 0.68 \\
\hline
\end{tabular}

Table 3a

\begin{tabular}{|c|c|c|c|c|c|}
\hline \multicolumn{6}{|c|}{ Standardized Regression Weights } \\
\hline & & & Estimate & & $p$-value \\
\hline Knowledge & $<--$ & Internal & 0.628 & & 0.000 \\
\hline Knowledge & $<--$ & External & 0.269 & & 0.012 \\
\hline Org System & $<--$ & Knowledge & 0.681 & & 0.000 \\
\hline Performance & $<--$ & Knowledge & -0.248 & & 0.102 \\
\hline Performance & $<--$ & Org System & 0.330 & & 0.034 \\
\hline \multicolumn{6}{|c|}{ Table $3 b$} \\
\hline \multicolumn{6}{|c|}{ Fit Measures } \\
\hline Discrepancy & & & \multicolumn{3}{|c|}{85.306} \\
\hline $\mathrm{P}$ & & & \multicolumn{3}{|c|}{0.118} \\
\hline Number of parameters & & & \multicolumn{3}{|c|}{48} \\
\hline Discrepancy / df & & & \multicolumn{3}{|c|}{1.201} \\
\hline Normed fit index (NFI) & & & \multicolumn{3}{|c|}{0.988} \\
\hline Relative fit index (RFI) & & & \multicolumn{3}{|c|}{0.982} \\
\hline Incremental fit index (IFI) & & & \multicolumn{3}{|c|}{0.998} \\
\hline Tucker-Lewis index (TLI) & & & \multicolumn{3}{|c|}{0.997} \\
\hline Comparative fit index (CFI) & & & \multicolumn{3}{|c|}{0.998} \\
\hline RMSEA & & & \multicolumn{3}{|c|}{0.031} \\
\hline RMSEA upper bound & & & \multicolumn{3}{|c|}{0.053} \\
\hline$P$ for test of close fit & & & \multicolumn{3}{|c|}{0.916} \\
\hline
\end{tabular}




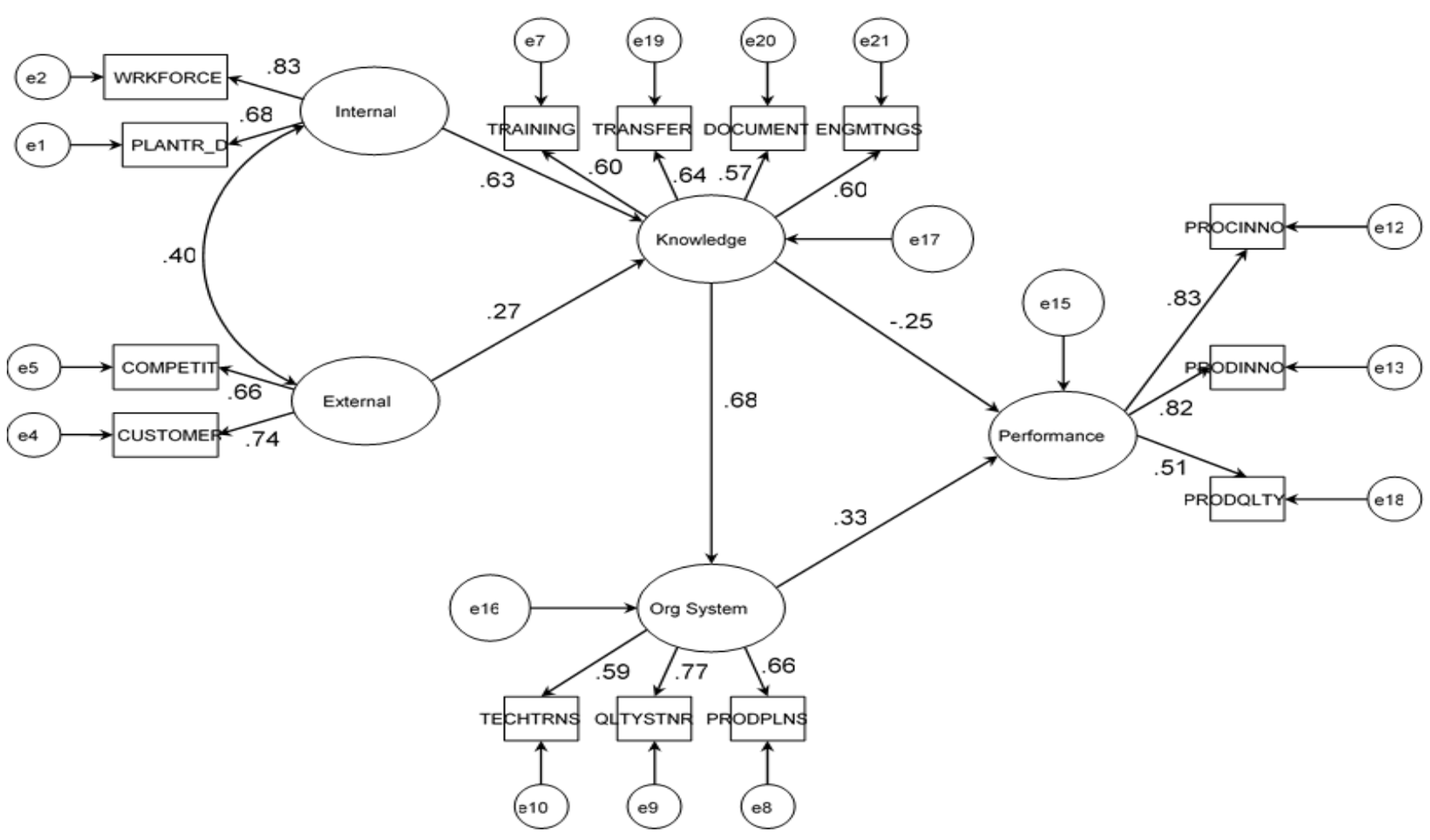

Figure 2

Table 4a

\begin{tabular}{|c|c|c|c|c|}
\hline \multicolumn{5}{|c|}{ Standardized Regression Weights (Alternate Model) } \\
\hline & & & & $p$-value \\
\hline Tacit & $<--$ & Internal & 0.670 & 0.000 \\
\hline Explicit & $<--$ & External & 0.252 & 0.039 \\
\hline Tacit & $<--$ & External & 0.269 & 0.023 \\
\hline Explicit & $<--$ & Internal & 0.737 & 0.000 \\
\hline Org System & $<--$ & Explicit & 0.323 & 0.121 \\
\hline Org System & $<--$ & Tacit & 0.392 & 0.064 \\
\hline Performance & $<--$ & Org System & 0.315 & 0.036 \\
\hline Performance & $<--$ & Explicit & -0.331 & 0.131 \\
\hline Performance & $<-$ & Tacit & 0.075 & 0.732 \\
\hline \multicolumn{5}{|c|}{ Table $4 \mathrm{~b}$} \\
\hline \multicolumn{5}{|c|}{ Fit Measures (Alternate Model) } \\
\hline Discrepancy & & & & 98.763 \\
\hline Degrees of freedom & & & & 67 \\
\hline $\mathrm{P}$ & & & & 0.007 \\
\hline Number of parameters & & & & 52 \\
\hline Discrepancy / df & & & & 1.474 \\
\hline Normed fit index (NFI) & & & & 0.986 \\
\hline Relative fit index (RFI) & & & & 0.977 \\
\hline Incremental fit index (IFI) & & & & 0.995 \\
\hline Tucker-Lewis index (TLI) & & & & 0.993 \\
\hline Comparative fit index (CFI) & & & & 0.995 \\
\hline RMSEA & & & & 0.048 \\
\hline RMSEA lower bound & & & & 0.026 \\
\hline RMSEA upper bound & & & & 0.067 \\
\hline $\mathrm{P}$ for test of close fit & & & & 0.554 \\
\hline
\end{tabular}


Hypotheses $1 \mathrm{a}$ and $1 \mathrm{~b}$ presented contrasting arguments in the research literature in an attempt to achieve some level of clarification. Hypothesis 1a suggested that knowledge transfer will have a positive direct effect on innovation performance, reflecting the perspective that organizations serve only to exploit innovations generated by individuals rather than having any direct role in the re-combinatory process itself (Grant 1996). On the other hand, Hypothesis $1 \mathrm{~b}$ argued that organizational systems will mediate the relationship between knowledge transfer and innovation performance, consistent with the view of the organization as having a central role in recombining the knowledge of the constituent individuals (Kogut \& Zander 1992). Our data and results show support for the re-combinatory role of organizational systems as Hypothesis $1 \mathrm{~b}$ is supported in the tested model. The paths between knowledge transfer and organizational systems and between organizational systems and innovation performance are both positive (.68 and .33 respectively) and significant $(p<.05)$. As a result, the standardized indirect effect of knowledge transfer on performance is .225. Tests, not presented here, that controlled for direct and indirect effects produced similar results convincing us that the effect of knowledge on innovation performance is in fact mediated by organizational systems.

In Hypothesis 2, we expected that transfer of knowledge within the organization would be more likely when the knowledge was generated internally as opposed to externally. Hypothesis 2 was also supported. While both sources of knowledge were significantly associated with the firms' base of knowledge $(p<0.05)$, internal sources proved to be a stronger predictor of knowledge base than external sources.

Although our above model combined the tacit and explicit dimensions of knowledge, as a robustness check, we tested an alternate model where these dimensions were tested separately. The results are presented in Tables $4 \mathrm{a}$ and $4 \mathrm{~b}$ which include the standardized regression weights and statistical significance for the model. The structural model is not presented here. This model separated knowledge into tacit and explicit dimension and the results are consistent with our original model that had a composite knowledge factor.

\section{Discussion}

Knowledge transfer appears to have an effect on innovation performance that is mediated by organizational systems. This suggests that rather than simply being a medium through which individually-conceived innovations are converted to commercial value, organizational systems play an important role in the knowledge recombination that leads to innovation. Additionally, knowledge transfer within the firm is heavily dependent on the organization system. In other words, a high level of standardization is required across the business units of the firm for it to successfully transfer technology within the firm. It is also important to recall here that the knowledge transfer of the firm was found to be most highly associated with its internal sources of knowledge.

The above findings provide several important implications for firms in regard to knowledge transfer and its effect on firm performance. First, it is interesting to note that, while the literature suggests that most managers place greater value on external sources of knowledge rather than internal sources of knowledge, it is the internal sources that contribute most to the firm's knowledge transfer. Our findings suggest that greater emphasis should be placed on programs to enhance knowledge generation from such internal sources as the workforce and the research and development teams.

Additionally, the results of the direct and indirect effects of knowledge transfer on innovation performance provide useful insight to the understanding not only of the role of knowledge itself but of the accompanying organizational systems designed to utilize that knowledge as well. Our data showed support for the indirect effects of knowledge transfer on innovation performance. This provides an important clarification that is currently missing in the extant literature. We presented two views regarding the role of knowledge and organizational systems in the firm's innovation process as commonly accepted by the strategic management community-one, where the role of the organizational system is to simply implement the knowledge held by the firm acting as an integrating mechanism, and hence suggesting that knowledge itself should have a direct effect on innovation, and two, where the role of the organizational system is to aid in the recombination of the knowledge base in order to generate innovation, where the organizational systems are part of the creative process and innovation. Hence, without the vital role played in the recombination of knowledge by the organizational system, the knowledge base itself is unable to affect performance. This view argues for a mediating role of organizational systems in the knowledge-performance relationship. The findings of the present study suggest a greater plausibility for the Kogut \& Zander (1992) view of organizational systems as only indirect effects of knowledge on innovation performance were supported and that this effect was in the presence of organizational systems as a mediator. This suggests that without appropriate systems established to utilize the knowledge generated by the firm, the knowledge will be unable to enhance the innovations of the firm. This finding not only offers clarity to the researcher but implications to the practicing manager as well. Greater emphasis should be placed on the organization of such systems to appropriately utilize such knowledge. While the development and gathering of knowledge is of vital importance, managers must realize that, without sufficient attention focused on the organizational system designed to organize and implement this knowledge, the knowledge itself will not provide the desired impact on performance. These findings are also borne out in recent efforts by corporations to create the best systems to appropriate the knowledge held by different individuals across different facets of the organization.

While the findings and structural model of the knowledge 
process presented in this paper are of statistical significance, we would like to acknowledge some limitations as well in order to caution the reader when generalizing the findings beyond the current study as well as to aide future researchers who aim to examine similar phenomenon. Several of those limitations pertain to the data itself. The reader should note that the methods used in the current study create a single-source bias as all of the data was collected from the same plant manager. In order to add to the robustness of the findings, future research should attempt to replicate the findings using objective performance data. In addition, utilizing multiple respondents from each firm represented would lessen the single-source bias. This is also important with respect to the dependent variables and collecting external measures of performance would be desirable.

Secondly, caution should be taken when generalizing beyond the manufacturing industry as all respondents represented manufacturing plants. While there appears to be no theoretical reason to doubt that similar processes would occur in other industries, future research should examine such questions. Thirdly, a note on causality should be made. While current theory suggests the direction of the causal paths presented in the structural model discussed in this paper, the nature of the data used in the present analysis prohibits the confirmation of causality.

Fourthly, the results presented in the present paper pertain to the model in which knowledge base is a single construct comprised of both tacit and explicit knowledge. This model is not only able to offer a significant fit over the alternate model in which the two types of knowledge are segregated, but offers parsimony as well. While this aggregation is consistent with the research literature, future research should examine whether these knowledge types are able to play significant roles in firm performance or if their role is only in terms of a combined construct as presented in this paper. Finally, different types and forms of innovation performance may be possible and the organizational systems may have differential impact on them. Future research could explicitly consider these alternate performance measures.

\section{Appendix A}

Internal sources of knowledge:

Please indicate to what extent each of the following possible sources of technology play a role in your business unit.

1. Plant level R\&D, Mfg. Eng., etc.

2. Work force

External sources of knowledge:

Please indicate to what extent each of the following possible sources of technology play a role in your business unit.

1. Customers

2. Competitors

\section{Knowledge Transfer:}

To what extent are the following methods used for accomplishing technology transfer in your business unit?

1. Formal training programs

2. Long-term personnel transfer

3. Internal documentation: manuals, reports, etc.

4. Scientific or engineering meetings

\section{Organizational Systems (Level of standardization):}

To what extent do the following factors contribute to achieving coordination / integration of manufacturing operations across plants in your business unit?

1. Technology transfer across plants in your business unit

2. Common quality standards across all plants

3. Similar production planning systems

\section{Innovation Performance:}

How well does your plant perform compared to the world standard (best possible performance) with respect to the following dimensions?

1. Process innovation

2. Product innovation

3. Product quality

\section{REFERENCES}

[1] Almeida, P. and Kogut, B. (1999), "Localization of knowledge and the mobility of engineers in regional networks", Management Science, Vol. 45 No. 7, pp. 905-917.

[2] Argote, L. (2013), Organizational Learning: Creating, Retaining and Transferring Knowledge, Organizational Learning: Creating, Retaining and Transferring Knowledge, 2nd ed., Springer US, available at:https://doi.org/10.1007/978-1-4614-5251-5.

[3] Argote, L., Beckman, S.L. and Epple, D. (1990), "The persistence and transfer of learning in industrial settings", Management Science, Vol. 36 No. 2, pp. 140-154.

[4] Barney, J.B. (1991), "Firm resources and sustained competitive advantage", Journal of Management, Vol. 17 No. 1, pp. 99-120.

[5] Cialdini, R.B. (2001), Influence: Science and Practice, 4th ed., Harper Collins, New York.

[6] Katz, R. and Allen, T. J. (1982), "Investigating the Not-Invented-Here (NIH) syndrome: A look at the performance, tenure and communication patterns of $50 \mathrm{R} \& \mathrm{D}$ prject groups", R\&D Management, Vol 12, pp. 7-19.

[7] Cohen, W.M. and Levinthal, D.A. (1990), "Absorptive capacity: A new perspective on learning and innovation", Administrative Science Quarterly, Vol. 35 No. 1, pp. 128-152.

[8] Conner, K.R.\& and Prahalad, C.K. (1996), “A Resource-Based Theory of the Firm: Knowledge Versus Opportunism", Organization Science, Vol. 7 No. 5, pp. 477501. 
[9] Edmondson, A.C., Bohmer, R.M. and Pisano, G.P. (2000), "Disrupted routines: Effects of team learning on new technology adaptation", Harvard Business School.

[10] Grant, R.M. (1996), "Toward a knowledge-based theory of the firm”, Strategic Management Journal, Vol. 17, pp. 109-122.

[11] Hansen, M.T. (2002), "Knowledge Networks: Explaining Effective Knowledge Sharing in Multiunit Companies.", Organization Science, INFORMS: Institute for Operations Research, Vol. 13 No. 3, pp. 232-248.

[12] Inkpen, A.C. and Tsang, E.W.K. (2005), "Social capital, networks, and knowledge transfer", Academy of Management Review, Vol. 30 No. 1, pp. 146-165.

[13] Kogut, B. and Zander, U. (1992), "Knowledge of the firm, combinative capabilities, and the replication of technology", Organization Science, Vol. 3, pp. 383-397.

[14] Maritan, C.A., Brush, T.H. and Karnani, A.G. (2004), "Plant roles and decision autonomy in multinational plant networks", Journal of Operations Management, Vol. 22 No. 5, pp. 489503.

[15] Menon, T. and Pfeffer, J. (2003), "Valuing internal vs. external knowledge: Explaining the preference for outsiders", Management Science, Vol. 49, pp. 497-513.

[16] Nonaka, I. (1994), "A dynamic theory of organizational knowledge creation”, Organization Science, Vol. 5, pp. 14-37.

[17] Nonaka, I. and Takeuchi, H. (1996), "The knowledge-creating company: How Japanese companies create the dynamics of innovation”, Long Range Planning, Vol. 29 No. 4, p. 592.

[18] Polanyi, M. (1966), The Tacit Dimension, Routledge and Kegan Paul, London, UK.

[19] Simon, H. a. (1991), "Bounded Rationality and Organizational Learning”, Organization Science, Vol. 2 No. 1, pp. 125-134.

[20] Spender, J.C. (1996), "Making knowledge the basis of a dynamic theory of the firm", Strategic Management Journal, Vol. 17, pp. 45-62.

[21] Szulanski, G. (1996), "Exploring Internal Stickiness: Impediments to the Transfer of Best Practice Within the Firm", Strategic Management Journal, John Wiley \& Sons, Vol. 17, pp. $27-43$.

[22] Szulanski, G., Ringov, D. and Jensen, R.J. (2016), "Overcoming Stickiness: How the Timing of Knowledge Transfer Methods Affects Transfer Difficulty", Organization Science, Vol. 27 No. 2, pp. 304-322.

[23] Zander, U. and Kogut, B. (1995), "Knowledge and the speed of the transfer and imitation of organizational capabilities - An empirical-test", Organization Science, Vol. 6 No. 1, pp. 76-92. 